\title{
The Impact of Food Habits on Pregnancy Outcome in A South Indian Population
}

\author{
Author \\ Surg lt* Devdatt laxman Pitale
}

Assistant Professor of Obstetrics and Gynaecology, Indian Naval Hospital Asvini, Colaba-400005

Ex Senior resident Obstetrics and Gynaecology, The Voluntary Health Services (VHS) Multispeciality

Hospital and Research Institute, Chennai

*Surgeon lieutenant

\begin{abstract}
Introduction: Nutrition during pregnancy plays an important role for an optimum outcome of pregnancy. Women may be malnourished even before they become pregnant and this may further adversely affect the pregnancy. Maternal undernutrition can lead to poor intrauterine growth and low weight of the baby at birth. Moreover, the leading causes for maternal deaths like hemorrhage and infection are related directly or indirectly to nutrition.
\end{abstract}

Aim of the Study: To study the impact of existing food habits on pregnancy outcome in a south Indian population.

Materials and Methods: This prospective study was conducted in the Department of Obstetrics and Gynecology, Voluntary Health services, Multi-specialty Hospital and Research Institute, Adyar, Chennai. The study was carried out between January 2013-July2014. From the antenatal clinic, 350 women who satisfied the following inclusion and exclusion criteria were admitted to the study.

Results: The majority of pregnant women belonged to the age group of 21-25 yrs (47\%) followed by the 26-30 yrs age group (40\%).The number of teenage pregnancies was 30 (8\%) whereas 5\% of pregnant women belong the age group of 31-35 yrs.83\% of the study population belonged to the low socioeconomic class.

Majority of the babies (66\%) had the birth weight in the range of 2.5-2.9 kgs. $29 \%$ of babies had birth weight in the range of 3-3.5 $\mathrm{kgs}$.

There was a significant association ( $p$ value $<0.05$ ) between the socioeconomic status of the mother, parity and her calorie intake. The present study found a statistically significant association between the maternal nutritional status, the birth weight of the baby and the need for NICU admission ( $p$ value < 0.05).

Conclusion: Maternal food habits have an impact on the pregnancy outcome. Maternal food habits are influenced by many factors like socioeconomic status, parity, social food taboos and pregnancy itself. The pregnancy outcomes like birth weight, need for NICU admission and postnatal complications are influenced by maternal nutritional status.

Keywords: Nutrition,Food habits, birth weight. 


\section{Introduction}

An adequate availability of nutrients during gestation is probably the single most important environmental factor influencing pregnancy outcome. An inadequate supply will risk the wellbeing of both mother and the conceptus.

A woman with poor nutritional status has an increased risk of complications like anemia and adverse pregnancy outcomes such as postpartum hemorrhage, preterm births and fetal growth retardation which in turn increases the risk of Prematurity and low birth weight.

Maternal nutrition is indirectly assessed by her weight gain during pregnancy. According to the guidelines of Institute of Medicine the total weight gain during the course of a singleton pregnancy for a healthy woman averages $11.5-16 \mathrm{~kg}$, with a weight gain of $1-3 \mathrm{kgs}$ during first trimester and about $0.35-0.5 \mathrm{kgs}$ per week during second and third trimester ${ }^{1}$.

Mothers are subjected to nutritional stress owing to the nursing process and their health risk is multiplied by frequent pregnancies, pregnancy complications like hyperemesis, coupled with a lack of access to and control over income, inadequate education, and excessive demands on their time, and so on ${ }^{2}$.As in many other countries, there are traditional beliefs in India regarding specific food items a pregnant woman should or should not eat during pregnancy. This leads to misconceptions like the belief of 'eating down' - the belief that pregnant women should eat less than before pregnancy or should not increase the diet during pregnancy quite widespread in India .Foods perceived as 'hot' in Tamil Nadu communities are more in number (papaya, pineapple, mango, animal foods, wheat and sesame seeds) $)^{3}$. Awareness of these being myths is not created in women. There is an urgent need to overcome the cultural practices that are traditionally affecting the nutritional and health status of women

There is no doubt that maternal nutrition during pregnancy plays an important role in optimum outcome of pregnancy. The present study was undertaken to study the impact of food habits on pregnancy outcome in a south Indian population.

\section{Materials and Methods}

This prospective study was conducted in the Department of Obstetrics and Gynecology, Voluntary Health services, Multi-specialty Hospital and Research Institute, Adyar, Chennai. The study was carried out between January 2013July2014. From the antenatal clinic, 350 women who satisfied the following inclusion and exclusion criteria were admitted to the study .A proper informed consent was obtained from all the mothers who were admitted to the study.

\section{Inclusion criteria}

1. All Pregnant women less than 40 years with gestational age $<24$ week

2. Women willing to come for regular antenatal checkups and delivery at the VHS

3. Willing to participate in the study

\section{Exclusion criteria}

1. Maternal complications such as diabetes, hypertension and other medical disorders

2. Bad obstetric history

3. Not willing to participate in the study

\section{Methodology}

From the antenatal clinic, 350 women who satisfied the inclusion and exclusion criteria were admitted to the study. At the first visit, a detailed history regarding her present pregnancy was recorded along with a detailed past obstetric history and family history. All pregnant women who participated in the study were interviewed at regular intervals of (14 to $16 \mathrm{wks}, 24$ to $26 \mathrm{wks}, 28$ to $30 \mathrm{wks}$ and 32 to $36 \mathrm{wks}$ of gestational age). During such visits Dietary intake of the subjects was assessed by 24-hour Recall method .Maternal weight, hemoglobin and fetal growth profile was noted during such visits. A general physical and obstetric examination was done at such visits. Nutritive value was calculated for every case. 


\section{Assessment of food habits}

In this study the dietary intake of the subjects was assessed by 24-hour Recall method.

\section{Follow up}

All the women who participated in the study were called for regular antenatal check-up and care was provided as per the routine protocol. During the regular antenatal check-ups, maternal weight gain, BMI, hemoglobin and fetal growth profile, was assessed. All the women were counseled about the importance of adequate nutrition. The onset of labor spontaneous or induced, type of delivery whether spontaneous vaginal delivery, instrumental vaginal delivery or LSCS was noted.

\section{Perinatal outcome}

The Perinatal outcome was assessed by the usual parameters of GA, birth weight, Apgar score and presence or absence of congenital anomalies.

\section{Statistical Analysis}

At the end of the study the impact of food habits on pregnancy outcome in terms of mode of delivery, birth weight and NICU admission was assessed and the results were analyzed using appropriate Chi-Square statistical method.

\section{Ethical justification}

This study did not involve any invasive procedures. However ethical justification was obtained from the ethical committee of the hospital.

\section{Results}

This prospective study was conducted to find out the impact of food habits on pregnancy outcome in a South Indian population. This prospective study was conducted in the Department of Obstetrics and Gynecology, Voluntary Health services, Multi-specialty Hospital and Research Institute, Chennai. The study was carried out between January 2013- July2014. From the antenatal clinic, 350 women who satisfied the inclusion and exclusion criteria were admitted to the study.
Characteristics of the women in the study Age distribution

Age distribution of women who participated in this study is shown in the table 1.

\begin{tabular}{|l|c|}
\hline TOTAL NOS $(\%)$ & AGE (YRS) \\
\hline $30(8)$ & $15-20$ \\
\hline $165(47)$ & $21-25$ \\
\hline $140(40)$ & $26-30$ \\
\hline $15(5)$ & $31-35$ \\
\hline 350 & TOTAL \\
\hline
\end{tabular}

From the above table it is seen that the maximum number of pregnant women belonged to the age group of 21-25 yrs (47\%) followed by the 26-30 yrs age group (40\%). The number of teenage pregnancies was $30(8 \%)$ whereas $5 \%$ of pregnant women belong the age group of 31-35 yrs.

\section{Parity}

The parity of the women who participated in this study is shown in the table 2 below

Table: 2

\begin{tabular}{|l|c|}
\hline TOTAL NOS $(\%)$ & PARITY \\
\hline $175(50)$ & G1 \\
\hline $152(43.5)$ & G2 \\
\hline $21(6)$ & G3 \\
\hline $2(0.5)$ & G4 \\
\hline 350 & TOTAL \\
\hline
\end{tabular}

From the above table it is seen that half of the pregnant women $(50 \%)$ in the study group were primigravidas and $(43.5 \%)$ were second gravidas. In this study, $6 \%$ and $0.5 \%$ of pregnant women were third and fourth gravidas respectively.

\section{Socio economic status}

The socio economic status of the respondents as per Kuppuswamy's classification

Table: 3 Socio economic statuses of the pregnant women

\begin{tabular}{|l|c|}
\hline TOTAL NOS $(\%)$ & INCOME GROUP \\
\hline $290(83)$ & LOWER \\
\hline $50(14)$ & UPPER LOWER \\
\hline $10(3)$ & MIDDLE LOWER \\
\hline 350 & TOTAL NOS \\
\hline
\end{tabular}

It is seen from the above table that $83 \%$ of the study population belonged to the low socioeconomic class $.14 \%$ and $3 \%$ of the study population belonged to the upper lower and middle lower socioeconomic class respectively. Majority of women in this study belong to low 
socioeconomic class this institute provides medical care especially to the patients belonging to the lower socioeconomic class on par with the upper socioeconomic class patients .

\section{Prepregnancy B.M.I}

The nutritional status of the women in the present study is been shown in the table 4:

\begin{tabular}{|c|c|}
\hline Total no $(\%)$ & B.M.I $\left(\mathrm{Kg} / \mathrm{m}^{2}\right)$ \\
\hline $4(1)$ & $<18.5$ \\
\hline $296(85)$ & $18.5-24.9$ \\
\hline $50(14)$ & $>25$ \\
\hline 350 & Total \\
\hline
\end{tabular}

The above table shows us the Prepregnancy B.M.I of the women who participated in the study. As seen in the above table majority of women $(85 \%)$ have the B.M.I in the range of $18.5-24.9 \mathrm{~kg} / \mathrm{m}^{2}$ .The percentage of women who were obese (B.M.I>25 Kg/m ${ }^{2}$ ) was $14 \%$.Only $1 \%$ of women had B.M.I less than $18.5 \mathrm{~kg} / \mathrm{m}^{2}$ suggestive of maternal malnutrition.

Figure 1 Prepregnancy B.M.I $\left(\mathrm{kg} / \mathrm{m}^{2}\right)$ of Pregnant Women

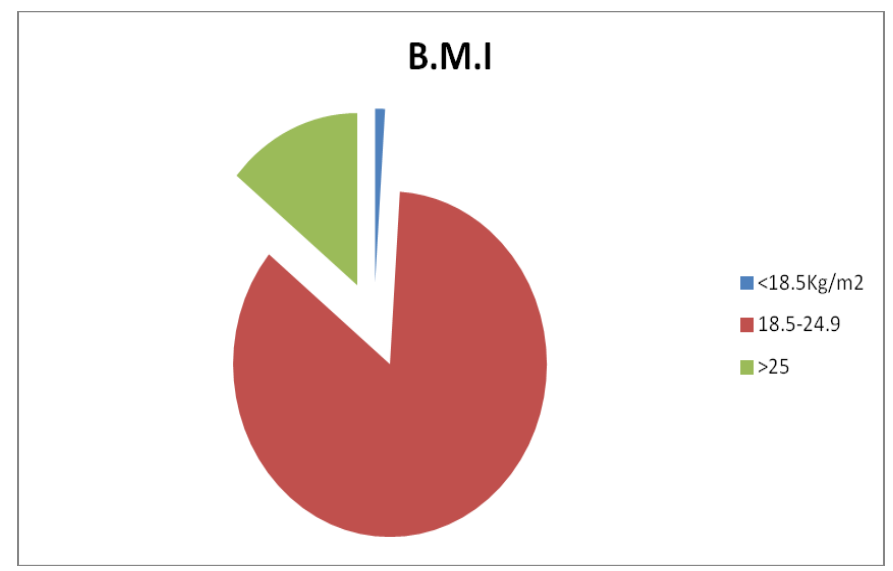

\section{Food habits of pregnant mothers}

Depending upon the B.M.I, the mothers in this study were divided into three major groups .The food items specifically consumed by the pregnant women who participated in this study is shown in the tables below.
Table 5 : Food items specifically consumed by the mothers belonging to different B.M.I groups

\begin{tabular}{|l|c|c|c|}
\hline$>25$ & $18.5-24.9$ & $\begin{array}{c}\text { B.M.I } \\
<18.5 \mathrm{~kg} / \mathrm{m}^{2} \\
\% \text { of } \\
\text { mothers }\end{array}$ & $\begin{array}{c}\text { FOOD } \\
\text { ITEMS }\end{array}$ \\
\hline 90 & 95 & 85 & Rice \\
\hline 54 & 68 & 75 & Milk \\
\hline 70 & 85 & 80 & Idly \\
\hline 40 & 17 & 25 & Rassam \\
\hline 56 & 47 & 50 & Apple \\
\hline 00 & 00 & 00 & Papaya \\
\hline 40 & 44 & 75 & Banana \\
\hline 60 & 51 & 50 & Eggs \\
\hline 60 & 50 & 50 & Dates \\
\hline 40 & 17 & 00 & Mutton soups \\
\hline
\end{tabular}

The above table shows the food habits of participant mothers belonging to different B.M.I groups. In all the three groups the mothers have added the nutritious food items in their diet.

In the mothers with low B.M.I, milk and banana was added by $75 \%$ of mothers followed by apple and dates by $50 \%$ of mothers.

In the mothers with B.M.I within normal range, milk was added by $68 \%$ of mothers followed by apples $(47 \%)$, dates $(50 \%)$ and bananas (44\%). Eggs were added by $51 \%$ mothers in their diet.

In the mothers with B.M.I $>25 \mathrm{~kg} / \mathrm{m}^{2}, 54 \%$ of mothers added milk followed by eggs $(60 \%)$,dates $(60 \%)$ and apples by $56 \%$ of mothers

\section{Association between the socioeconomic status and calorie intake}

The association between the socioeconomic status and calorie intake of the mothers is shown in the table 6

Table 6 : Socioeconomic satus and Calorie Intake

\begin{tabular}{|l|c|c|c|c|}
\hline Visit4 & VIsit3 & Visit2 & $\begin{array}{c}\text { Visit1 } \\
\text { Calories } \\
(\mathrm{kcal} / \mathrm{kg})\end{array}$ & SES \\
\hline 2139.1 & 2134.4 & 2063.1 & 1991.2 & LIG \\
\hline 2179.4 & 2171.0 & 2132.2 & 2036.0 & MIG \\
\hline 0.006 & 0.144 & 0.023 & 0.136 & P - Value \\
\hline
\end{tabular}

The above table 6 , shows the association between the calorie intake and socioeconomic status. As shown in the above table, there is a significant association between the socio-economic status of the mother and the calorie intake. 


\section{Calorie Intake}

The average calorie intake of the mothers belonging to different groups during each visit is shown in table 7

\begin{tabular}{|l|l|l|l|l|}
\hline \multicolumn{4}{|c|}{ CALORIES (kcal/day) } & \multirow{2}{*}{ B.M.I $\left(\mathrm{kg} / \mathrm{m}^{2)}\right.$} \\
\cline { 1 - 4 } $\begin{array}{l}32-36 \\
\text { wks }\end{array}$ & $\begin{array}{l}28-30 \\
\text { wks }\end{array}$ & $\begin{array}{l}24-26 \\
\text { wks }\end{array}$ & $14-16$ wks & \\
\hline 1950 & 2125 & 1750 & 1640 & $<18.5$ \\
\hline 2100 & 2150 & 2000 & 1800 & $18.5-24.9$ \\
\hline 2000 & 2050 & 1950 & 1900 & $>25$ \\
\hline
\end{tabular}

The above table shows us the average calorie intake of the mothers belonging to different B.M.I groups. The highest calorie intake during the first visit (1900 kcal/day) was seen in the mothers belonging to the $>25 \mathrm{~kg} / \mathrm{m}^{2}$ B.M.I group, whereas the least calorie intake during the first visit (1640 $\mathrm{kcal} /$ day) was seen in the mothers with B.M.I $<18.5 \mathrm{~kg} / \mathrm{m}^{2}$.In the mothers belonging to B.M.I within normal range $\left(18.5-24.9 \mathrm{~kg} / \mathrm{m}^{2}\right)$ the calorie intake during the first visit was $1800 \mathrm{kcal} /$ day.

In all the three groups there has been a fall in calorie intake during the last visit as compared to the calorie intake in the third visit. The maximum fall in calorie intake was seen in the mothers with B.M.I $<18.5 \mathrm{~kg} / \mathrm{m}^{2}$ (1950kcal/day). The calorie intake in the mothers with B.M.I within normal range and mothers with B.M.I $>25 \mathrm{~kg} / \mathrm{m}^{2}$ was reduced to $2100 \mathrm{kcal} /$ day and $2000 \mathrm{kcal} /$ day respectively.

\section{Mode of delivery of participant mothers}

The mode of the delivery of the participant mothers is shown in the table 8

\begin{tabular}{|l|c|}
\hline TOTAL NOS $(\%)$ & MODE OF DELIVERY \\
\hline $229(65)$ & NORMAL \\
\hline $16(5)$ & INTRUMENTAL \\
\hline $105(30)$ & CESAREAN \\
\hline 350 & TOTAL \\
\hline
\end{tabular}

Above table shows the mode of delivery for the pregnant women who participated in this study. As shown in the above table maximum number of women $(65 \%)$ had a normal delivery. About $30 \%$ of women underwent a cesarean section. Only 5\% of the pregnant women underwent an instrumental delivery.

\section{Birth weight}

Birth weight of the babies of the participant mothers is shown in table 9

\begin{tabular}{|l|c|}
\hline Number of babies (\%) & Birth weight in kgs \\
\hline $20(5 \%)$ & $2-2.49$ \\
\hline $230(66 \%)$ & $2.5-2.99$ \\
\hline $100(29 \%)$ & $3-3.5$ \\
\hline 350 & Total number \\
\hline
\end{tabular}

The above tables shows the birth weight of the babies in the present study. Majority of the babies $(66 \%)$ had the birth weight in the range of 2.5-2.9 kgs $.29 \%$ of babies had birth weight in the range of $3-3.5 \mathrm{kgs} .5 \%$ of babies had birth weight in the range of 2-2.49 kgs.

\section{Association between the parity and calorie intake}

Table 10: Parity and Calorie Intake

\begin{tabular}{|l|c|c|c|c|}
\hline Visit4 & VIsit3 & Visit2 & $\begin{array}{c}\text { Visit1 } \\
\text { calories }\end{array}$ & $\begin{array}{c}\text { Parity } \\
\text { code }\end{array}$ \\
\hline 2139.1 & 2127.0 & 2060.3 & 1990.3 & P1 \\
\hline 2145.0 & 2146.2 & 2084.6 & 2002.6 & P2 \\
\hline 2206.3 & 2200.0 & 2113.2 & 2050.0 & P3 \\
\hline 2110.0 & 2140.0 & 2010.0 & 1900.0 & P4 \\
\hline 0.335 & 0.035 & 0.297 & 0.050 & P - Value \\
\hline
\end{tabular}

Above table shows the association between parity and the calorie intake of the pregnant women. As per the statistical analysis, there is a significant association between parity and calorie intake during the pregnancy. There is a declining trend in the calorie intake especially in multiparous mothers.

\section{Calorie Intake and Birth Weight}

The association between the calorie intake and birth weight of the baby is shown in the table 12

Table 12: calorie intake and birth weight

\begin{tabular}{|l|c|c|c|c|}
\hline Visit4 & VIsit3 & Visit2 & Visit1 & Wt (kg) \\
\hline 1900.0 & 1913.6 & 1795.5 & 1663.6 & $2-2.49$ \\
\hline 2115.8 & 2117.9 & 2025.6 & 1968.2 & $2.5-2.99$ \\
\hline 2197.6 & 2183.1 & 2140.2 & 2051.4 & $3-3.49$ \\
\hline 2129.2 & 2122.9 & 2106.3 & 2018.8 & $\geq 3.5$ \\
\hline 0.000 & 0.000 & 0.000 & 0.000 & P - Value \\
\hline
\end{tabular}


Above table shows the association between the calorie intake of pregnant mother and weight of the baby at birth. As shown in the above table, there is a very significant association between the calorie intake of the mother and birth weight of the baby. Proper calorie intake of the mother has a positive impact on the baby weight.

\section{Calorie Intake and NICU Admission}

In the present study 3 babies had NICU admission for the fetal distress.

The association between the calorie intake of the mother and need for NICU admission for fetal distress is shown in the table 12 .

Table 13: Association between the calorie intake and NICU admission at birth

\begin{tabular}{|l|c|c|c|c|}
\hline Visit4 & VIsit3 & Visit2 & Visit1 & NICU \\
\hline 2097.5 & 2060.0 & 2100.0 & 1987.5 & Yes \\
\hline 2145.6 & 2140.7 & 2072.9 & 1997.9 & No \\
\hline 0.000 & 0.046 & 0.392 & 0.188 & P - Value \\
\hline
\end{tabular}

Table 13 shows the association between the calorie intake and the (NICU) Neonatal intensive care unit admission at birth for fetal distress.

\section{Condition at discharge}

All the mothers who participated in this study were discharged on third day in case of a normal delivery and on eighth day in case of a cesarean section.

All the babies including those admitted in NICU were discharged on day 3 after checking their bilirubin levels.

There was no case of neonatal death, postnatal complications like puerperal sepsis and anemia in this study.

\section{Discussion}

An adequate availability of nutrients during gestation is probably the single most important environmental factor influencing pregnancy outcome. Although physiological adjustments in nutrient utilization and metabolism are geared to improve the utilization of dietary nutrients during pregnancy, these adjustments may be insufficient to meet the demands for pregnancy and lactation if the woman is in poor nutrient status at conception. An adequate supply of nutrients is required to maintain the delicate balance between the needs of the mother and those of the fetus. An inadequate supply will cause a state of biological competition between the mother and the conceptus in which the well-being of both is at serious risk ${ }^{4}$.

All societies have traditional beliefs regarding harmful and beneficial foods for women during, pregnancy. There are also beliefs regarding the optimal amount of food to be taken during pregnancy for a successful reproductive outcome. These beliefs may or may not conform to the modem biomedical notions about the proper types and amount of food needed by pregnant women to safeguard maternal nutrition, adequate growth of fetus and safe delivery .This prospective study was conducted to study the impact of food habits on pregnancy outcome in a south Indian population.

\section{Factors affecting the maternal nutrition Socioeconomic status}

In this study majority of the women ( $83 \%$ ) belonged to lower socioeconomic class as per Kuppuswamy's classification. $14 \%$ of women belonged to upper lower class and $3 \%$ belonged to middle lower socioeconomic class respectively. The present study found a statistically significant association ( $\mathrm{p}$ value $<0.05$ ) between the socioeconomic status and calorie intake of the mothers. Ayesha et $\mathrm{al}^{5}$ reported the impact of maternal socioeconomic limitations on the calorie intake.

\section{Parity}

The majority of women in this study were primigravida $(50 \%)$ or second gravida $(43.5 \%)$. $6 \%$ and $0.5 \%$ of women were of birth order 3 and 4 . The present study found a significant associateion between the parity and maternal calorie intake 


\section{Food habits and pregnancy outcome Mode of delivery}

In the present study $65 \%$ of women delivered normally. $30 \%$ of women underwent a cesarean section and $5 \%$ of women had instrumental deliveries. The present study shows no statistically significant association between the mode of delivery and calorie intake ( $\mathrm{p}$ value $>0.05$ ).

\section{Birth weight}

In the present study $66 \%$ of the babies had birth weight in the range of $2.5-2.9 \mathrm{kgs} .29 \%$ of babies had birth weight in the range of 3-3.5 kgs and 5\% of babies had birth weight in the range of 2-2.49 kgs respectively.

The present study found a very significant association between the maternal calorie intake and birth weight of the baby.

\section{NICU Admission}

In the present study 3 babies had NICU admission for fetal distress. The present study found a statistically significant association between the maternal calorie intake and the NICU admission.

The mothers whose preprgnancy BMI was low were given nutritional advice and it was noted that there was a marginal increase in their caroric intake in subsequent visits. However, this is not sufficient to influence the pregnancy outcome.

All these mothers belonging to low SE group are covered under the ICDS scheme and receive nutritional supplement during the entire pregnancy.

\section{Conclusion}

Among the 350 women who participated in this study majority of the women belonged to the age group of 21-30 yrs and to a lower socioeconomic class with the pre-pregnancy B.M.I within normal range of $18.5-24.9 \mathrm{~kg} / \mathrm{m}^{2}$.

The average calorie intake of mothers with normal B.M.I was $2012 \mathrm{kcal} /$ day. The average calorie intake of mothers with B.M.I $<18.5 \mathrm{~kg} / \mathrm{m}^{2}$ and mothers with B.M.I >25 was $1866 \mathrm{kcal} /$ day and $1975 \mathrm{kcal} /$ day respectively.

The food items consumed by the mothers during pregnancy consisted of rice, sambhar, milk, idly, fruits like apple, banana, dates, rassam and mutton soups. There was a significant association ( $\mathrm{p}$ value $<0.05$ ) between the socioeconomic status of the mother, parity and her calorie intake. The present study found a statistically significant association between the maternal nutritional status ,the birth weight of the baby and the need for NICU admission ( $p$ value $<0.05$ ).

Maternal food habits have an impact on the pregnancy outcome. Maternal food habits are influenced by many factors like socioeconomic status, parity, social food taboos and pregnancy itself. The pregnancy outcomes like birth weight, need for NICU admission and postnatal complications are influenced by maternal nutritional status.

\section{Conflicts of Interest}

The author declares no conflicts of interest

\section{Author Contributions}

Principal Author - Surg 1t.Dr Devdatt 1 Pitale

Contribution to the Paper - Performed analysis,data interpretation, manuscript writing and acted as corresponding author.

\section{Acknowledgements}

This research was supported by the VHS Hospital.I thank all my professors and Colleagues from the VHS for their support. I especially thank our HOD Dr S.Janaki, Prof.Ratnakumar, Dr Sarala Gopalan, Dr Esakiammal and Dr Naseem P Amir for their assistance with methodology and for comments that greatly improved the manuscript.

\section{References}

1. Institute of Medicine.Weight Gain During Pregnancy: Reexamining the Guidelines. Washington, DC: National Academy Press; 2009.

2. Asha K, Salil S. Nutrient Intake of Lactating Mothers from Rural areas and urban areas. Indian J Soc Res. 1998;39:2.

3. Nag, M. (2009). Beliefs and Practices about Food during Pregnancy: Implica- 
tions for Maternal Nutrition. Economic And Political Weekly, 29(37), 2427-2438.

4. Wahid MA, Fathi SA. Nutrition and the unborn baby. Ric Clin Lab. 1987;17(3):199-206.

5. Ayesha et Al.Impact of maternal education and socioeconomic status on maternal nutritional knowledge and practices regarding iron rich foods and iron supplements. Ann Pak Inst Med. Sci. 2012;8:101-5. 